\title{
Evaluation of Antioxidant Activity from Different Plant Parts of Senduduk Herb: Extraction Conditions Optimization of Selected Plant Part
}

\author{
Nor Helya Iman Kamaludin ${ }^{1, *}$, and Nor Syahida Adila Jaafar ${ }^{1}$ \\ ${ }^{1}$ Department of Chemical Engineering Technology, Faculty of Engineering Technology, Universiti \\ Malaysia Perlis (UniMAP), Perlis, Malaysia.
}

\begin{abstract}
This work reports a study on evaluation of antioxidant properties from flower of Senduduk herb. Natural occurring antioxidant was mostly preferred due to their little or no toxicity compared to the synthetic antioxidants which posses carcinogenic effects. Extraction was done on selected plant parts of Sendududk herb including leaves, stem, flower and berry parts to evaluate their antioxidant potentiality. Flower part of Sendudk herb extracted using acetonic solvent promotes highest antioxidant activity which is $93.97 \pm 1.38 \%$ as compared to leaves $(92.20 \pm 0.20 \%)$, stem (47.94 $\pm 1.42 \%)$ and berry $(92.88 \pm 0.63 \%)$ using the same extracting solvent. Thus, Senduduk flower was chosen to be continued with screening and optimization process. Single factor experiment using the one factor at a time (OFAT) method was done to study the effect of each extraction parameter that was solid to solvent ratio, temperature and solvent concentration. The extraction condition in each parametric study which results in highest antioxidant activity was used as the middle level of optimization process using Response Surface Methodology (RSM) coupled with Central Composite Design (CCD). The optimum condition was at 1:20 solid to solvent ratio, $64.61{ }^{\circ} \mathrm{C}$ temperature and $80.24 \%$ acetone concentration which result in antioxidant activity of $96.53 \%$. The verification of RSM showed that the model used to predict the antioxidant activity was valid and adequate with the experimental parameters.
\end{abstract}

\section{Introduction}

The requirement or demand towards natural antioxidants has increases in recent years especially in food and supplements industry. Most of people prefer something natural as their antioxidant source in order to maintain healthy life. Therefore, this situation has given rise to interest in studying herbal as natural antioxidants. This is because herbal are easy to obtain as they can be found abundantly in our country and also they have more economic value as compared to synthetic antioxidants. Furthermore, synthetic antioxidants may contain undesirable side effects such as toxics and carcinogenic properties when being used as food additives, therefore their uses being limited [1].

\footnotetext{
* Corresponding author: helya@unimap.edu.my
} 
Senduduk herbs with scientific name Melastoma malabathricum L. (Melastomataceae) is one of the herbal that have high potential to be commercialized as natural antioxidant sources. This herb has attained as one of the herbs status in the Malay folklore belief among Melastomatacae family in our country [2]. Potential as antidiarrhoic drugs, antiperglycemic, antihypertensive, antihyperglycemic, hemostatic, and antioxidants have been reported among numerous species of this family in conventional folk medicine $[3,4]$.

Solvent extraction is one of extraction method that was routinely used for the isolation of antioxidants from plant material. The antioxidant activity of extracts are strongly dependent on various extraction parameters such as solid to solvent ratio, temperature and solvent concentration. Therefore, the aim of this research is to evaluate the potentiality of different part of Senduduk Herb as a source of antioxidants. In fact, the optimum operating conditions was being examined as well for better extraction efficiency.

\section{Materials and method}

This section explains the sequences of steps required in this research activities. The first step involves the collection and preparation of sample. Next, the extraction using specific solvents was conducted in two screening steps including screening of Senduduk plant parts and screening of extraction parameters prior proceed to optimization studies using Design of Experiment (DOE) software.

\subsection{Sample Preparation}

Flower of Senduduk herb was collected from Pekan, Pahang. The herbal plant then was washed under tap water to removes any impurities and dirts. The samples were dried using conventional oven at $50^{\circ} \mathrm{C}$ for 24 hours and later was grind into smaller size using domestic blender. The ground plant parts are then kept in the separate closed container for later used.

\subsection{Solvent extraction}

The extraction was done using specific solvent in thermal-control water bath shaker. $2.5 \mathrm{~g}$ of samples were placed in $250 \mathrm{ml}$ conical flask and $50 \mathrm{ml}$ of solvent was added and then placed in thermostatic water bath shaker at $40{ }^{\circ} \mathrm{C}$ for 4 hours and shook at $150 \mathrm{rpm}$. The extracts were then filtered using Whatman No.1 filter paper to separate the liquid extract from solids. The solvent used was then removed by using rotary evaporator prior being analyzed.

\subsection{Screening of senduduk plant parts and solvent types}

Screening of plant part and type of solvent were performed by extracting different plant parts of Senduduk herbs including leaves, flower, stem and berry with different types of solvent (distilled water, methanol, ethanol and acetone) for evaluation of antioxidant activity. The plant part and solvent type that contribute to the highest antioxidant activity will be selected for further study of their extraction parameter.

\subsection{Screening of extraction parameters of selected plant part using OFAT}

Screening of extraction parameters was done using classical One-Factor-at-a-Time (OFAT) method. Using this approach, effect of temperature, extraction time and concentration of solvent on antioxidant activities of selected plant parts of Senduduk herbs were studied by evaluating each parameter while the others parameter are keep constant. 


\subsubsection{Effect of Solid to Solvent Ratio on Antioxidant Activity}

To study the effect of solid to solvent ratio on antioxidant activity, the flower of Senduduk herb was extracted with solid to solvent ratio of 1:05, 1:10, 1:20, 1:30 and 1:40 at $40{ }^{\circ} \mathrm{C}, 150$ rpm for 2 hours at concentration of $100 \%$. The best solid to solvent ratio was chosen according to the highest antioxidant activity (\%).

\subsubsection{Effect of Temperature on Antioxidant Activity}

To study the effect of temperature on antioxidant activity, the best solid to solvent ratio selected at previous step was used to extract Senduduk flower at different temperatures (45, $55,65,75,85){ }^{\circ} \mathrm{C}$ by fixing the concentration of $100 \%$ for 2 hours. The best temperature was chosen according to the highest antioxidant activity (\%).

\subsubsection{Effect of Concentration of Solvent on Antioxidant Activity}

To study the effect of concentration of solvent on antioxidant activity, the best solid to solvent ratio and temperature selected at previous steps were used at different concentration of solvent $(20 \%, 40 \%, 60 \%, 80 \% 100 \%)$. The best concentration of solvent was chosen accordingly to highest antioxidant activity (\%).

\subsection{Optimization using Response Surface Methodology (RSM)}

Optimization of extraction process was conducted by using Design-Expert software (Version 7.1.5). Response Surface Methodology coupled with Central Composite Design (CCD) at three level $(-1,0$ and +1$)$ was employed. The factors that were optimized include solvent to solid ratio, temperature and solvent concentration while the response variable was the antioxidant activity. A second order equation for two factors was developed by multiple regression procedure using the general equation (1):

$$
Y=\beta_{0}+\sum_{i-1}^{3} \beta_{i} X_{i}+\sum_{i-1}^{3} \beta_{i i} X^{2}+\sum_{i-1}^{2} \sum_{j-1+1}^{3} \beta_{i j} X_{i} J_{i}+\varepsilon
$$

Where $\mathrm{Y}$ is the predicted response ( $\% \mathrm{DPPH}), \beta_{0}$ is the model constant, $\beta_{i}, \beta_{i i}$, and $\beta_{i j}$ are model coefficients (linear, squared and interactive effects), and $\varepsilon$ is the error. Analysis-of-Variance (ANOVA) was performed for comparison of means. Regression analysis was performed and independent variables $3 \mathrm{D}$ surfaces were plots for analysis.

\subsection{Analysis: determination of antioxidant activity}

The 2,2-diphenyl-1-picrylhydrazyl (DPPH) radial-scavenging activity was determined by the method described by Jamal et al. [5] with slight modification. $250 \mu$ of the extract was diluted with distilled water to $10 \mathrm{ml}$. Next, $200 \mu \mathrm{l}$ of the aliquots were mixed with $2 \mathrm{ml}$ of 100 $\mu \mathrm{M}$ DPPH methanolic solution. Then, this mixture was placed at room temperature for 60 minutes in dark environment. The absorbance reading of the mixture was measured at 520 $\mathrm{nm}$. The following equation (2) was used to calculate the ability to scavenge of DPPH radical.

$$
\text { DPPH scavenging effect }(\%)=\frac{A_{0}-A_{1}}{A_{0}} \times 100
$$


where,

$\mathrm{A}_{0}=$ the absorbance of the control at $60 \mathrm{~min}$

$\mathrm{A}_{1}=$ the absorbance of the sample at $60 \mathrm{~min}$

\section{Result and discussion}

This section discusses on the results obtained through several analysis steps. There are three main sub-sections starting with discussion on the screening results of Senduduk plant parts and extraction parameters from selected plant part followed by analysis on optimization studies.

\subsection{Screening of senduduk plant parts and solvent types}

The result of DPPH scavenging activity among different plant parts of Senduduk herbs are shown in Table 1. In general, the percentage of DPPH inhibition among different plant parts ranging from $34.90 \pm 1.00$ to $93.97 \pm 1.38 \%$. In comparison to the various parts of Senduduk herbs, methanolic stem extract showed least effectiveness in DPPH scavenging activity with only $34.90 \pm 1.01 \%$ of radical inhibition. Meanwhile, acetonic extracts of three plant parts of Senduduk flower, berry and leaves possess the highest antioxidant activity among the extracts with percentage of inhibition were $93.97 \pm 1.38,92.88 \pm 0.63$ and $92.20 \pm 0.20 \%$, respectively. Thus, it can be concluded that acetone was the best solvent for the extraction of antioxidant activity of Senduduk herb. This is in agreement with Martin et al., [6] which states that acetone can be considered as a quite efficient solvent for the extraction of phenolic substances which responsible for antioxidant activity.

Table 1. Screening of different plant parts of Senduduk herb and solvent types on antioxidant activity

\begin{tabular}{|c|l|c|}
\hline Plant Part Extract & Type of Solvent (pure) & Antioxidant Activity (\%) \\
\hline \multirow{3}{*}{ Leaves } & Distilled water & $87.58 \pm 0.24$ \\
\cline { 2 - 3 } & Methanol & $85.61 \pm 0.45$ \\
\cline { 2 - 3 } & Acetone & $92.20 \pm 0.20$ \\
\cline { 2 - 3 } & Ethanol & $86.68 \pm 0.23$ \\
\hline \multirow{2}{*}{ Stem } & Distilled water & $88.00 \pm 0.76$ \\
\cline { 2 - 3 } & Methanol & $34.90 \pm 1.01$ \\
\cline { 2 - 3 } & Acetone & $47.94 \pm 1.42$ \\
\cline { 2 - 3 } & Ethanol & $86.42 \pm 2.09$ \\
\hline \multirow{2}{*}{ Flower } & Distilled water & $85.79 \pm 0.70$ \\
\cline { 2 - 3 } & Methanol & $79.93 \pm 0.57$ \\
\cline { 2 - 3 } & Acetone & $93.97 \pm 1.38$ \\
\cline { 2 - 3 } & Ethanol & $67.53 \pm 1.04$ \\
\hline \multirow{2}{*}{ Berry } & Distilled water & $88.20 \pm 0.37$ \\
\hline & Methanol & $93.31 \pm 0.11$ \\
\cline { 2 - 3 } & Acetone & $86.78 \pm 0.28$ \\
\cline { 2 - 3 } & Ethanol & \\
\hline
\end{tabular}

Remarks:

Lowest AA

Highest AA 


\subsection{Screening of extraction parameters of senduduk flower using one factor at a time (OFAT)}

\subsubsection{Effect of Solid to Solvent Ratio on Antioxidant Activity}

The antioxidant activity of flower of Senduduk herb was significantly affected by solid to solvent ratio as the probability $\mathrm{P}$-values is higher than $0.05(\mathrm{P}>0.05)$. From Figure 1 , the best solid to solvent ratio were obtained at 1:20 with the highest DPPH scavenging activity of $81.89 \pm 1.87 \%$. According to Tan et al., [7] higher solid to solvent ratio could result in the higher antioxidant activity. This was due to the increase in concentration gradient between solid and the solvent that acts as the driving force for the mass transfer. This phenomenon was observed at a range of 1:05 to 1:20, where antioxidant activity showed significantly increased from $73.74 \pm 1.86$ to $81.89 \pm 1.87 \%$. However, further increased in the ratio up to $1: 40$ resulted in the reduction of antioxidant activity. This could be caused by saturation of solvent occurred at 1:20 and thus the final equilibrium were achieved [8]. Therefore, 1:20 solid to solvent ratio was selected as the best solid to solvent ratio to be used for further study of other effect in OFAT approach.

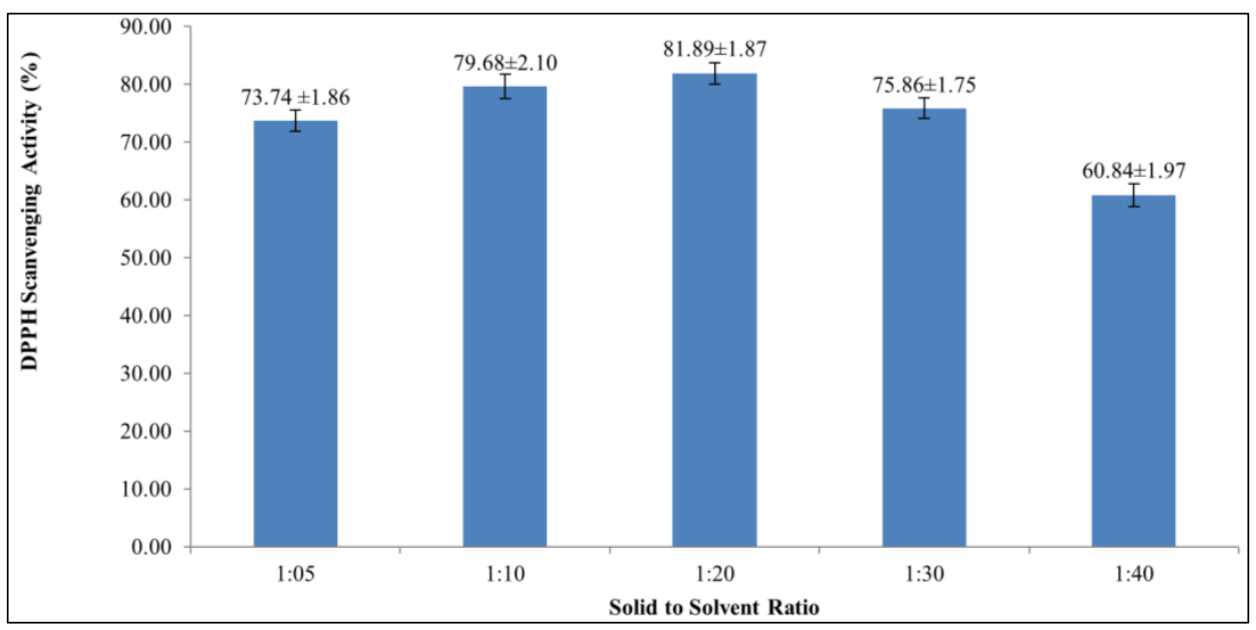

Fig. 1. Effect of solid to solvent ratio on antioxidant activity from flower of Senduduk herb.

\subsubsection{Effect of temperature on antioxidant activity}

Meanwhile, the effect of temperature on antioxidant activity of Senduduk flower is shown in Figure 2. A significant increased of antioxidant activity was observed from $79.03 \pm 2.17 \%$ to $95.88 \pm 2.50 \%$ as the temperature increased from $45^{\circ} \mathrm{C}$ to $65^{\circ} \mathrm{C}$. This was due to at higher extraction temperature, the solubility of analyte would increase and thus promotes higher rates of mass transfer. Hence, the extraction efficiency could be improved and thus allow the solvent reach to the sample matrices easily. However, beyond $65^{\circ} \mathrm{C}$, the antioxidant activity starts to decrease. These might due to the degradation of thermo-sensitive phenolic compound such us flavonoids that was heat sensible [9]. Therefore, $65^{\circ} \mathrm{C}$ was selected as the best temperature to be used for further study of other effect in OFAT approach. 


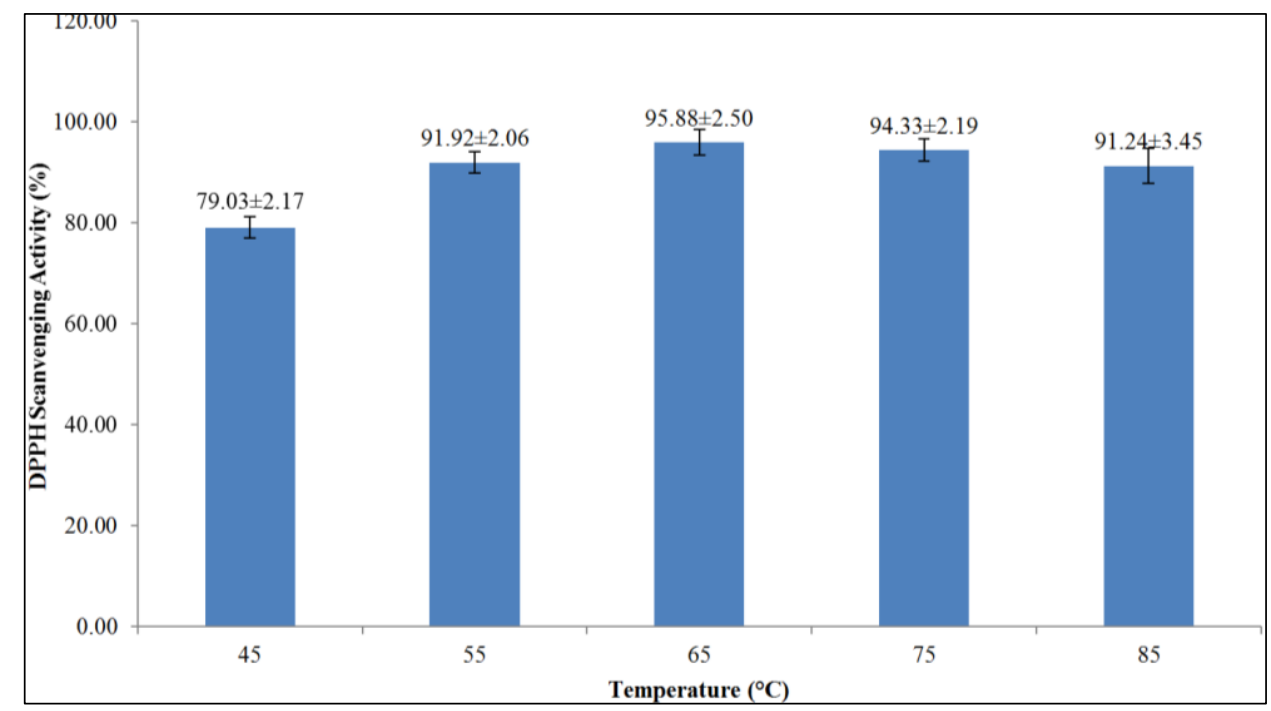

Fig. 2. Effect of temperature on antioxidant activity from flower of Senduduk herbs.

\subsubsection{Effect of Solvent Concentration on Antioxidant Activity}

The antioxidant activity as a function of solvent concentration was shown in Figure 3. Results indicated that there is a significant increase in antioxidant activity from $84.74 \pm 0.58 \%$ to $87.56 \pm 0.23 \%$ with the increasing of acetone concentration from $20 \%$ to $80 \%$. However, the further increase in solvent concentration up to $100 \%$ results in the decrease of antioxidant activity. This is in agreement with Fatma et al., [10] that stated the extraction using a mixture of organic solvent and water could promotes higher recovery of antioxidant phenolic compounds as compared using of pure organic solvent due to the polarity effects. Therefore, acetone with concentration of $80 \%$ was selected as the best concentration of solvent to extract antioxidant activity from flower of Senduduk herb.

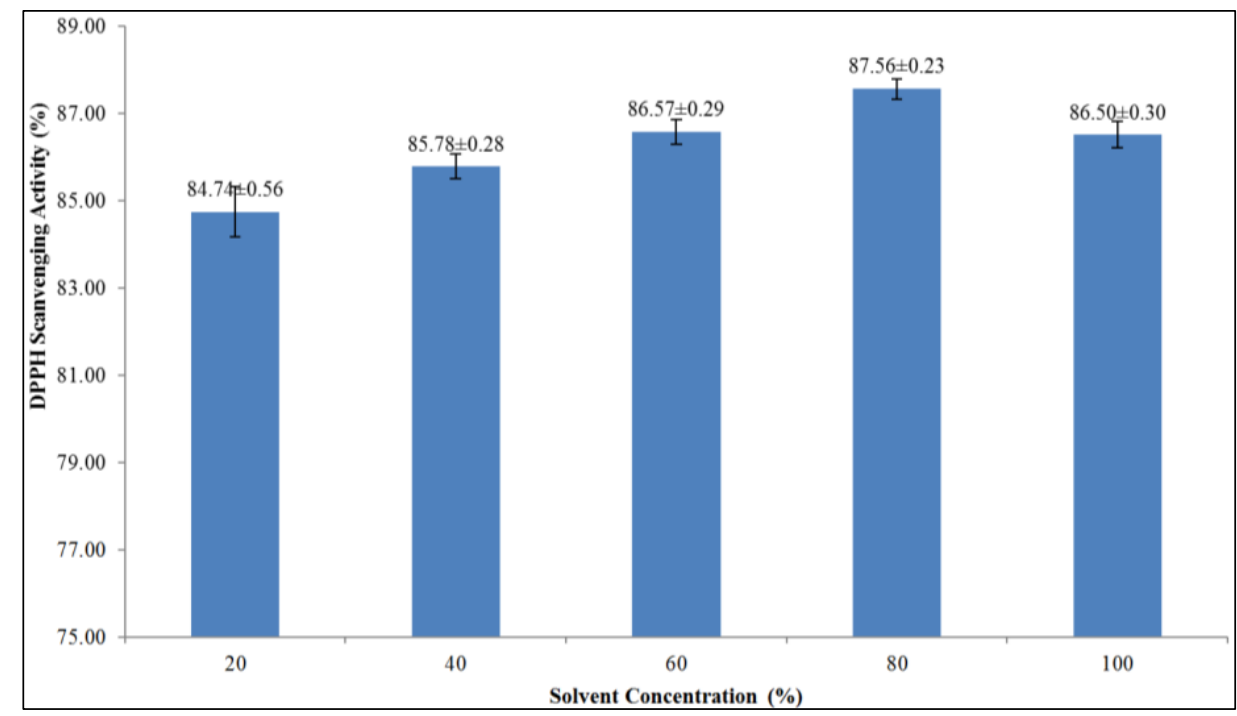

Fig. 3. Effect of solvent concentration on antioxidant activity of flower of Senduduk herb. 


\subsection{Optimization studies}

Central composite design (CCD) with three factors and five levels were used in this study to optimize the DPPH scavenging activity of Senduduk herb flowers. Twenty run of extraction condition with eight factorial points, six axial points and six repetition of central point was given in Table 2. The result indicates that the highest antioxidant activity (97.05\%) of Senduduk herb flower was shown by Run 8 which lies within the central point at 1:20 solid to solvent ratio, $65^{\circ} \mathrm{C}$ temperature and $80 \%$ acetone concentration. The residual error obtained was only $0.61 \%$ for both experimental and predicted values. Based on the results in Table 2, second order equation was developed as shown in equation (3) where $\mathrm{X}_{1}$ is solid to solvent ratio, $\mathrm{X}_{2}$ is the temperature and $\mathrm{X}_{3}$ is solvent concentration.

Antioxidant activity $=+96.44-0.67 \mathrm{X}_{1}-0.31 \mathrm{X}_{2}+0.083 \mathrm{X}_{3}-0.020 \mathrm{X}_{1} \mathrm{X}_{2}-0.092 \mathrm{X}_{1} \mathrm{X}_{3}$

$$
+0.019 \mathrm{X}_{2} \mathrm{X}_{3}-1.39 \mathrm{X}_{1}^{2}-1.94 \mathrm{X}_{2}^{2}-1.8403 \mathrm{X}_{3}^{2}
$$

Table 2. The experimental and predicted design of CDD from flower of Senduduk herb

\begin{tabular}{|c|c|c|c|c|c|c|}
\hline \multirow{2}{*}{ Run } & \multirow{2}{*}{$\begin{array}{c}\text { Solid to } \\
\text { solvent } \\
\text { ratio }\end{array}$} & \multirow{2}{*}{$\begin{array}{c}\text { Temperature } \\
(\mathbf{g} / \mathbf{C})\end{array}$} & \multirow{2}{*}{$\begin{array}{c}\text { Solvent } \\
\text { concentration } \\
\mathbf{( \% )}\end{array}$} & & \multicolumn{3}{|c|}{ Antioxidant activity (\%) } \\
\cline { 5 - 7 } & & & Experimental & Predicted & $\begin{array}{c}\text { Residual } \\
(\%)\end{array}$ \\
\hline 1 & 0.05 & 65.00 & 63.18 & 90.78 & 91.09 & 0.31 \\
\hline 2 & 0.05 & 65.00 & 80.00 & 95.57 & 96.44 & 0.87 \\
\hline 3 & 0.05 & 65.00 & 96.82 & 90.03 & 91.37 & 1.34 \\
\hline 4 & 0.04 & 70.00 & 90.00 & 92.24 & 92.01 & -0.23 \\
\hline 5 & 0.05 & 56.59 & 80.00 & 90.25 & 91.47 & 1.22 \\
\hline 6 & 0.05 & 65.00 & 80.00 & 96.41 & 96.44 & 0.03 \\
\hline 7 & 0.04 & 70.00 & 70.00 & 91.84 & 91.29 & -0.55 \\
\hline 8 & 0.05 & 65.00 & 80.00 & 97.05 & 96.44 & -0.61 \\
\hline 9 & 0.05 & 65.00 & 80.00 & 95.48 & 96.44 & 0.96 \\
\hline 10 & 0.07 & 60.00 & 90.00 & 91.34 & 90.73 & -0.61 \\
\hline 11 & 0.08 & 65.00 & 80.00 & 90.48 & 91.37 & 0.89 \\
\hline 12 & 0.04 & 60.00 & 90.00 & 93.53 & 92.21 & -1.32 \\
\hline 13 & 0.05 & 65.00 & 80.00 & 97.04 & 96.44 & -0.60 \\
\hline 14 & 0.03 & 65.00 & 80.00 & 92.86 & 93.62 & 0.76 \\
\hline 15 & 0.04 & 60.00 & 70.00 & 92.36 & 92.23 & -0.13 \\
\hline 16 & 0.07 & 70.00 & 90.00 & 91.48 & 90.44 & -1.04 \\
\hline 17 & 0.05 & 73.41 & 80.00 & 90.00 & 90.43 & 0.43 \\
\hline 18 & 0.05 & 65.00 & 80.00 & 97.35 & 96.44 & -0.91 \\
\hline 19 & 0.07 & 60.00 & 70.00 & 92.05 & 92.05 & 0.00 \\
\hline 20 & 0.07 & 70.00 & 70.00 & 89.94 & 90.09 & 0.15 \\
\hline
\end{tabular}

Note: Run 2, 6, 8, 9, 13, 18 represents the centre points.

Condition shows the highest antioxidant activity

Condition shows the lowest antioxidant activity 


\subsection{Model analysis}

In fact, in order to investigate the interactive effect of independent variables on the optimization of extraction condition from Senduduk flower, three dimensional (3D) plots were examined for the estimated response. Figure 4 represents the combination effect of two variables on the response. As shown in Figure 4 (a), a response surface plot for interaction effect of temperature and solid to solvent ratio at a fixed $80 \%$ solvent concentration on antioxidant activity was illustrated. From the figure, it can be observed that solid to solvent ratio and temperature has a simultaneous effect on antioxidant activity. The scavenging rate increased up to $97.35 \%$ with the increasing of the temperature from $60^{\circ} \mathrm{C}$ to $65^{\circ} \mathrm{C}$ at solid to solvent ratio of $1: 20$. However, beyond $65^{\circ} \mathrm{C}$ the scavenging effect starts to decrease. This could be caused by degradation of phenolic compound that contribute to reduction in antioxidant activity as they are easily oxidized [11]. Cacae and Mazza [12] also stated that the decreased of antioxidant activity at higher temperature was due to degradation of thermo-sensitive phenolic compound that was heat sensible.

The interaction effect of solid to solvent ratio and solvent concentration on antioxidant activity at fixed extraction temperature of $65^{\circ} \mathrm{C}$ was shown in Figure 4 (b). The result revealed that the antioxidant activity increased up to $97.35 \%$ with the increament of solvent concentration from 70 to $80 \%$ and solid to solvent ratio of 1:20. The increasing trends of antioxidant activity with respect to solid to solvent ratio was demonstrated by the mass transfer principle. At higher solid to solvent ratio, the concentration gradient between the solid and the liquid solvent also was higher and thus could promote the leaching of the bioactive compound to the solid matrix, and hence better extraction rate could be obtained [13][14]. However, further increased in solid to solvent ratio and solvent concentration beyond 1:20 and $80 \%$, respectively gave negative effects on antioxidant activity. This could be caused by saturation of solvent occurred at 1:20 and thus achieved their final equilibrium [8].

Figure 4 (c) demonstrated the interactive effect between solvent concentration and temperature at constant solid to solvent ratio of 1:20. The result indicates that an increase in solvent concentration from $70 \%$ to $80 \%$ and temperature from $60^{\circ} \mathrm{C}$ to $65^{\circ} \mathrm{C}$ resulting an increase in antioxidant activity up to $97.35 \%$. However, the declined trends were observed in antioxidant activity when the solvent concentration was kept increase to $90 \%$. This might be due to a decrease in polarity of acetone as more polar solvent will facilitates the extraction of phenolic compound [10]. 

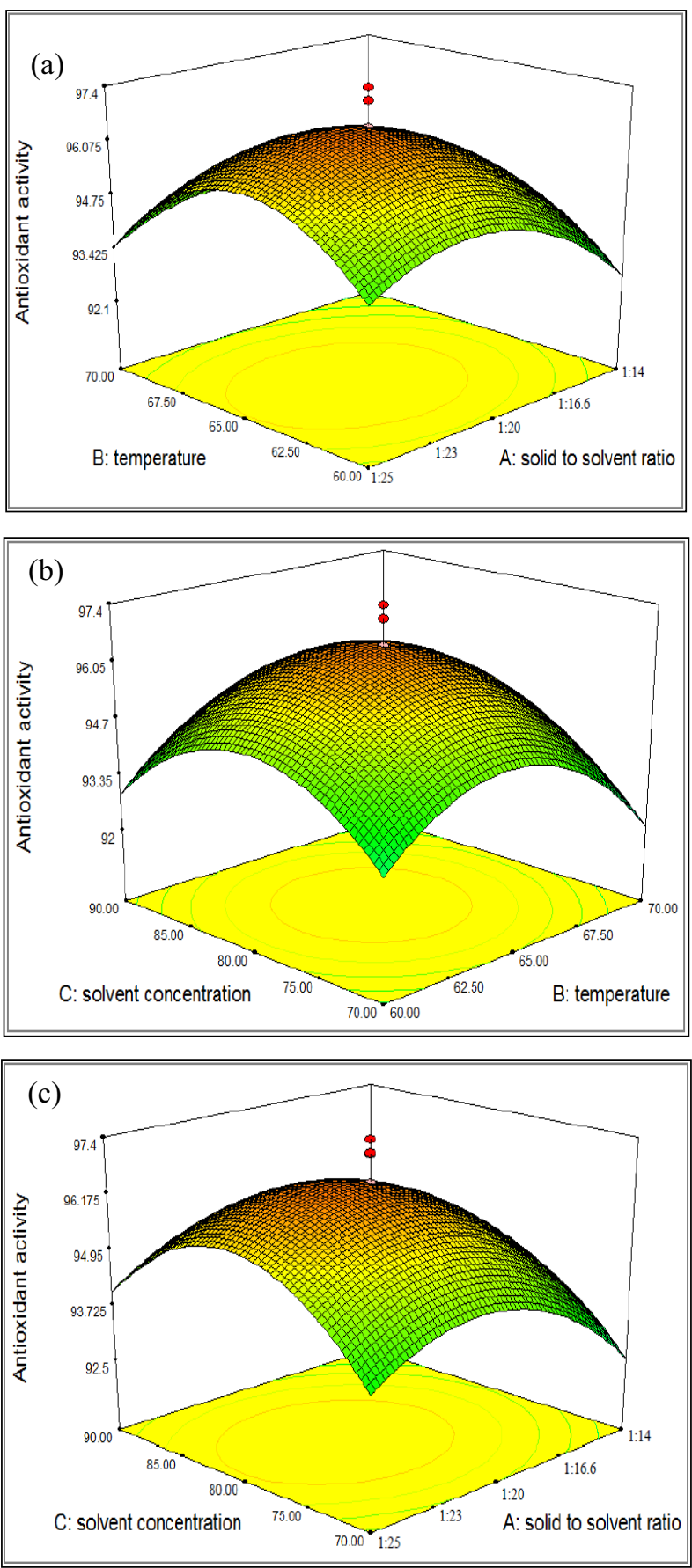

Fig. 4. 3D response surface plot for the effect of (a) solid to solvent ratio and temperature (b) solid to solvent ratio and solvent concentration (c) temperature and solvent concentration on antioxidant activity 


\section{Conclusion}

For overall view, the antioxidant activities was detected exist in Senduduk herbal plants. Flower part with acetonic extracts showed the highest antioxidant activity of $93.97 \pm 1.38 \%$ as compared to the other three plant parts (leaves, stem and berry) of Senduduk herb tested. Through OFAT approach, the antioxidant activities of Senduduk flower was significantly affected by various extraction parameters studied including solid to solvent ratio, temperature and solvent concentration. The extraction was continued in optimization by using Response Surface Methodology (RSM) with Central Composite Design (CCD). The optimum process parameters for maximum antioxidant activity were determined and a second order polynomial model for predicting the response was obtained. The highest antioxidant activity of $96.53 \%$ was obtained at optimum extraction conditions at 1:20 solid to solvent ratio, $64.61^{\circ} \mathrm{C}$ temperature and $80.24 \%$ acetone concentration. The verification of RSM showed that the model was valid and adequate for the optimum extraction conditions of antioxidant activity. Therefore, CCD and RSM enabled the determination of optimal condition for the extraction of antioxidant activity from flower of Senduduk herb.

The authors would like to express their appreciations to Faculty of Engineering Technology, Universiti Malaysia Perlis (UniMAP) for facilitating this project.

\section{References}

1. S.C. Jo, K.C. Nam, B.R. Min, D.U. Ahn, S.H. Cho, W.P. Park, S.C. Lee, Int. J. Food Sci. Tech., 41, 15 (2006).

2. K. Meyer, Journal of Plant Taxonomy and Plant Geography, 46, 351 (2001)

3. D. Susanti, H.M. Sirat, F. Ahmad, R.M. Ali, N. Aimi, M. Kitajima, Food Chem., 103, 710 (2007)

4. J.T. Cheng, F.L. Hsu, H.F. Chen, Planta. Med., 59, 405 (1993)

5. P. Jamal, Z.M. Idris, M.Z. Alam, Food Chem., 124, 1595 (2010)

6. S. Martins, C.N. Aguilar, J.A. Teixeira, S.I. Mussatto, Sep. Purif. Technol., 88, 163 (2012)

7. P.W. Tan, C.P. Tan, C.W. Ho, Int. Food Res. J., 18, 557 (2011)

8. E.M. Silva, H. Rogez, Y. Larondelle, Sep. Purif. Technol., 55, 381 (2007)

9. J.E. Cacace, G. Mazza, J. Food Eng., 59, 379 (2003)

10. F. Kallel, D. Driss, F. Chaari, L. Belghith, F. Bouaziz, R. Ghorbel, S.E. Chaabouni, Ind. Crops. Prod., 62, 34 (2014)

11. Y.Y. Thoo, S.K. Ho, J.Y. Liang, C.W. Ho, C.P. Tan, Food Chem., 120, 290 (2010)

12. J.E. Cacace, G. Mazza, J. Food Eng., 59, 379 (2003)

13. M.A. Al Farsi, C.Y. Lee, Food Chem., 108, 977 (2008)

14. P.W. Tan, C.P. Tan, C.W. Ho, Int. Food Res. J., 18, 557 (2011) 